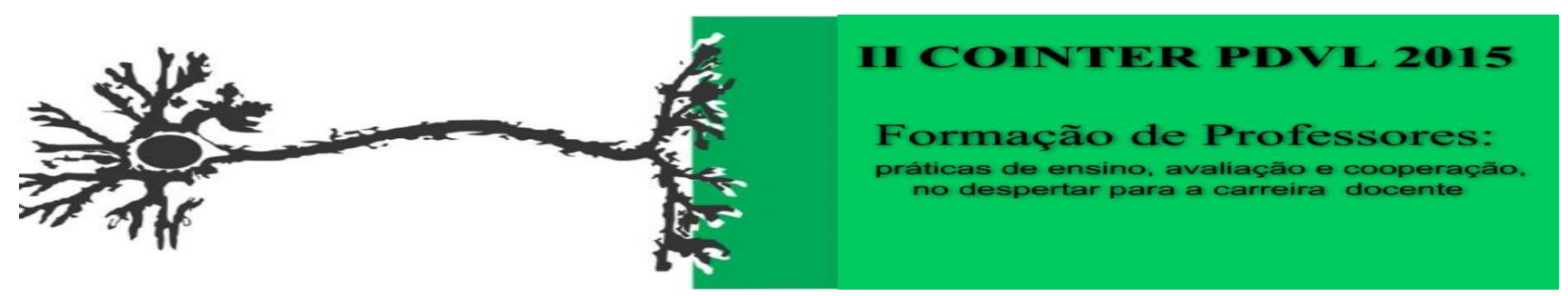

\title{
GERENCIAMENTO E PRODUÇÃO DE MATERIAIS DE APRENDIZAGEM AUDIOVISUAIS PARA O ENSINO DE QUÍMICA
}

\author{
Apresentação: Relato de Experiência \\ Kleyfton Soares da Silva ${ }^{1}$; Pollyanne Christine R. Freire ${ }^{2}$; Mayrane Carla Marques do \\ Nascimento $^{3}$; Johnnatan Duarte de Freitas ${ }^{4}$
}

\section{Introdução}

Discussões que tratam de metodologias que atendam os objetivos da educação brasileira e da realidade contemporânea vivenciada pelos alunos revelam a necessidade da utilização de recursos tecnológicos em sala de aula. Amaral (2006) enfatiza que a simples transmissão de informações pode ser feita de forma mais interessante, com recursos de animação e de som, desenvolvendo novas formas de lidar com o conhecimento disponível. Além disso, o programa auxilia o professor em sua formação e no desenvolvimento criativo, reflexivo e crítico dos alunos (MOURA et al., 2011).

O presente relato trata dos resultados da realização de uma oficina intitulada "Utilização do Windows Movie Maker para a Criação de Filmes Educativos” para 16 licenciandos em química do Instituto Federal de Alagoas - Campus Maceió, como parte das ações do PIBID/IFAL Subprojeto de Química. A oficina teve como objetivos treinar e incentivar futuros professores para a utilização de recursos tecnológicos integrados à metodologia de projetos para o desenvolvimento de ferramentas educacionais. O Microsoft Windows Movie Maker ${ }^{\circledR}$ (MWMM) é um software livre para criação e edição de vídeos amadores. Este recurso é parte integrante do sistema operacional Windows® e possibilita ao usuário dinamizar as criações por meio da manipulação de imagens, sons, vídeos e textos.

Portanto, acreditamos que o gerenciamento e produção de recursos audiovisuais por meio do software citado é uma alternativa metodológica significativa para inovar no ensino de química.

\section{Relato de Experiência}

Os participantes tiveram a oportunidade de aprender como utilizar o programa MWMM e produziram vídeos educativos abordando a história da Tabela Periódica. Para isso, eles fizeram um

\footnotetext{
${ }^{1}$ Licenciatura em Química, IFAL, kley.soares@hotmail.com

2 Licenciatura em Química, IFAL, pollyanne@outlook.com

${ }^{3}$ Mestranda, IFAL, mayrane.carla@hotmailcom

${ }^{4}$ Doutor, IFAL, johnnatandf@gmail.com
} 
planejamento simples das etapas de desenvolvimento do vídeo e pesquisaram imagens, sons e vídeos relacionados à tabela periódica com a finalidade de editá-los e transformá-los em uma única mídia. Um questionário aberto foi aplicado para registrar as experiências dos participantes.

A experiência com o desenvolvimento de vídeos educativos permitiu ampliar as possibilidades metodológicas para o ensino de ciências, tendo em vista a necessidade de representar vários conceitos científicos de forma mais elaborada, dinâmica e atrativa. Um participante destacou que a proposta da criação e utilização de vídeos "é uma ideia válida para apresentar assuntos mais abstratos e teóricos da química". Rosa (2000) destaca, porém, que os recursos audiovisuais precisam ser cuidadosamente planejados, analisados e aplicados, pois estes não podem servir como um substituto para a falta de tempo para preparar uma aula.

A variedade de abordagens ao tema proposto que os participantes apresentaram na conclusão dos vídeos mostrou o quanto a criatividade pode ser estimulada, além disso, muitas foram as propostas para a criação de outros vídeos. "Produzir um vídeo para o assunto de funções inorgânicas e a importância delas no dia a dia", disse um participante sobre ideias para futuras edições usando o programa. Outro licenciando acrescentou que "criar um vídeo a partir de fotos e, o melhor, transformar em uma ferramenta metodológica para melhorar a aprendizagem em química, é fantástico".

\section{Considerações}

Os resultados da atividade prática foram positivos e incentivaram os futuros professores no sentido de fazê-los refletir sobre novas abordagens metodológicas através de ferramentas educacionais estimuladoras. Outra alternativa é propor aos alunos que criem vídeos com os resultados de atividades de laboratório e/ou pesquisa na escola.

\section{Referências}

AMARAL, S. F. As novas tecnologias e as mudanças nos padrões de percepção da realidade. In: NAKASHIMA, Helena Ruiz. Pesquisas em Educação, Comunicação e Tecnologia. ETD Educação Temática Digital, Campinas, v.8, dez. 2006.

Moura, E. S. Aguiar, J. G. Boyen, J. Rebellato, M. Movie Maker e formação de professores: uma relação a ser construída. ÀGORA, Porto Alegre, Ano 2, jan./jun. 2011.

Rosa, P. R. S. O uso dos recursos audiovisuais e o ensino de ciências. Cad.Cat.Ens.Fís., v. 17, n. 1: p. 33-49, abr. 2000. 